\title{
Agent-Based Fire Evacuation Model as a Tool for Fire Safety Design Assessment in Malaysia
}

\author{
Tan Yi Rong ${ }^{1}$, Farid Akashah ${ }^{2}$ and Norhayati Mahyuddin ${ }^{3}$ \\ ${ }^{12}$ Centre for Construction, Building and Urban Studies (CeBUS), Faculty of Built Environment, University of Malaya, Kuala \\ Lumpur, Malaysia \\ ${ }^{3}$ Urban Conservation and Tropical Architecture (UCTA), Faculty of Built Environment, University of Malaya, \\ Kuala Lumpur, Malaysia \\ 1ontyr@siswa.um.edu.my, ${ }^{2}$ faridakashah@um.edu.my, ${ }^{3}$ hayati@um.edu.my
}

\begin{abstract}
Evacuation model is an important tool in formulating performance-based building design. It is a tool aims at helping designers assess the robustness of their design against factors such as human behaviour in fire. Currently, performance-based code for fire safety design has been the hot trend all over the world. Nevertheless, even though Malaysia is applying prescriptive-based code, performance-based approach for special buildings and mega projects are allowed. This shows that it is just a matter of time before performance-based code be fully adopted in place of prescriptive-based code in Malaysia. This paper aims to highlight how evacuation modelling may help designers assess the performance of their design. In this paper, an example of evacuation scenario was modelled and simulated using an agent-based fire evacuation model - FDS+Evac. The output of the simulation provide graphical representation such as the fire curve, the evacuation time, and the time to untenable condition that can be used to analyse the life safety objective based on concepts of ASET and RSET. The FED values of all occupants throughout the evacuation process are less than tenability criteria ( 0.3 FED). Therefore, it is concluded that all occupants have evacuated safely in the event of fire.
\end{abstract}

Keywords: agent-based, evacuation model, fire safety design, human behaviour, performance-based code

\subsection{INTRODUCTION}

Worldwide movement is heading towards performance-based code from the traditional method of prescriptive-based code since 1990s (Alvarez et al., 2013; Bryan, 2002b; Meacham, 1996, 1999). In the past three decades, more and more countries around the world have permitted or required their building regulatory system to include the performance-based approach. Some of the countries like Canada (National Building Code of Canada, NBCC), UK (British Standard Code of Practice, BS), Australia (Building Code of Australia, BCA), New Zealand (Building Act 2004), and Japan (Building Standard Laws and Regulation in 2000) have already transformed their building regulatory system into performance-based codes.

\subsection{Fire Safety Design - Prescriptive-Based Code and Performance-Based Code}

Before performance-based code was introduced, the building regulatory system for fire safety design was based on prescriptive-based code. Prescriptive-based code is an approved documents, detailed recommendation or classification that is deemed to be satisfied during the design of fire safety in building. As an example, the building code in Malaysia i.e. Uniform Building By-Laws (UBBL) 1984, is a prescriptive-based code which state exactly how a building should be built in order to satisfy fire safety requirements. However, this system does not explain how the fire safety is being reached (Tavares, 2009). In other terms, designer or any professional in the construction field have to "blindly" follow the requirements stated in the prescriptive-based code without having a clear idea how those requirements were developed and how it can assure fire safety in the building. Indirectly, this can lead to higher costs of design and it was claimed that those requirements in the prescriptive code may not provide adequate safety for the occupant (Tavares, 2009). 
Performance-based code, on the other hand, improves the regulation system by providing clearer guidance than prescriptive-based code (Tavares, 2009), taking into account advances made in the knowledge of fire science and fire safety engineering principles (Alvarez et al., 2013). Performance-based code allowed the fire safety in the building to be designed based on the performance of all the main aspects (i.e. fire, building and occupant). In the view of clients, goal of fire safety design does not only for the purpose of occupant life safety but they would also look into how it can assure business continuity and reduce property loss. Some may also look into the impact on environment. Performance-based code provides means to issue those goals.

In the process of performance-based design, fire safety is aimed to achieve goals and objectives established by the stakeholders, which then translated and quantified by fire safety engineers into performance/acceptable criteria (Alvarez et al., 2013). In the process, the consequences of fire safety design (e.g. frequency of fire occurrence, person death per year, expected annual loss of properties, building condition for business continuity, etc.) were evaluated based on selected design fire scenarios and its outcomes are compared with the performance criteria. With that, several fire safety engineering solutions could be developed. In order to perform the evaluation, appropriate supporting tools are required (Alvarez et al., 2013; Meacham, 1996). These tools do not only include the fire engineering guidelines and documentation as mentioned earlier, but also include computational modelling tools that can be used to evaluate the fire development, evacuation of occupants, performance of building structure and protection system in the design fire scenarios.

\subsection{Situation of Building Code in Malaysia}

In Malaysia, building design and construction, including fire safety design, are mainly governed by prescriptive-based code in the form of UBBL 1984. Client and design team would need to satisfy the requirements mentioned in the UBBL 1984 in terms of the dimension, material used, structural ability and number of the building components (i.e. staircase, compartmentation, ventilations, as well as mechanical system such as sprinkler and detectors). Building drawings need to be approved by the authorities and constructions that did not comply with the code will not be certified for operation.

However, this very code does allow fire safety engineering solutions to be used as a mean to comply with fire safety requirements. As abovementioned, performance-based code allows the fire safety objectives to be clearly defined. Client and design team have the freedom to define criteria and methodologies to achieve those objectives. They have more flexibility in making design decision and innovative solutions could be introduced. New technologies in the market are used to evaluate the fire safety for design decision. More solutions could be established for the clients and this enable fire safety design to reduce cost (Tavares, 2009).

Design of firefighting equipment or fire safety installation that is not mentioned by any of the fire safety requirements in the UBBL 1984 is acceptable and applicable under this building code provided that the design has gained approval from the Authority Having Jurisdiction (AHJ). Of course, it should expected that this fire safety design is able to provide a better, if not, an equivalent level of safety than the one based on prescribed requirements. This could be done by implementing the performance-based approach. This shows that fire safety engineering solutions is an important method that can be used to provide enough protection in accordance to fire safety requirements stated in the UBBL 1984. It can be claimed that UBBL 1984 is in actual fact does somehow adopt performance-based approach.

As such, UBBL 1984 is a code that has been developed to allow the transition process from prescriptive-based code to performance-based code to take place in Malaysia. In fact, this has taken place as evident in the construction of iconic buildings in Malaysia e.g. Kuala Lumpur Petronas Twin Tower and special building e.g. Kota Kinabalu International Airport (KKIA) and The Gardens - Midvalley Megamall, Kuala Lumpur (Scientific Fire Services, n.d.).

\subsection{Challenges in the Implementation of Performance-based Code}

Alvarez et al. (2013) pointed out both technical and political issues during the design decision process and fire engineering analysis in the implementation of performance-based approach. Technical issue is the decisions related to scientific or technological phenomenon. This included uncertainties in the areas such as the knowledge of science and engineering available in models, the human behaviour, and the societal view (i.e. cultural differences). Policy issue is related to decisions in the regulatory process involving social, cultural, technical and legal factors.

Alvarez et al. (2013) also mentioned eight challenges that need to be addressed in the performance-based fire protection design process as per the list shown below:

1. Codes, standards and guidelines are too generic for every types of building;

2. Current available performance criteria in the literatures are generic and does not describe the level of performance achieve by the building; 
3. There is no specific guidance for the selection of design fire scenarios for specific building;

4. Comparing levels of performance between engineering solution and one with prescriptive requirements is not an appropriate practice for performance-based approach, especially when aiming to fulfil fire safety goals other than life safety;

5. It is too complex in determining the influential factors which would influence the evaluation of fire safety design;

6. The "idealized" design features may not provide an idealized performance in the "real life" installation and running features;

7. Tools selection and user ability of using the tools are essential when estimating the consequences of design fire scenarios; and,

8. Literature values and database to use in models are not consolidated.

\subsection{Challenges in the Implementation of Performance-based Approach: Malaysia's Perspective}

In order to evaluate if the performance-based code are well implemented in a country, Tavares (2009) stated three criteria: 1) perception of fire safety by society; 2) centralised fire safety code; and, 3) support from government.

As aforementioned, the fire safety design in Malaysia is governed under the UBBL 1984. There are some other supporting guidelines (i.e. Malaysia Standards, British Standards, Eurocode) that were cited in the regulation. Yet, the development and implementation of fire safety code are centralised throughout the whole Malaysia territory. There is also Ministry of Fire and Rescue Department (i.e. BOMBA) with the responsibility to assure the implementation of fire safety code in fire safety design. These may bring to the ease of implementing performance-based approach in Malaysia as it has a centralised fire safety code established by the government. However, there is lack of perception of fire safety by the society which may be one of the challenges for Malaysia to implement performance-based approach successfully.

Besides, there is also lack of education in the knowledge of fire science and safety engineering in Malaysia (i.e. there is currently no fire engineering course provided in any of the university), the application of fire and evacuation modelling is not acquainted as well. As mentioned in previous section, implementing performance-based approach and providing fire safety engineering solutions required the knowledge of the science and technologies in the field of fire engineering. More qualification and skills of new technologies in the fire safety market are required to be introduced into Malaysia. This country lack the professional in scientific knowledge on fire engineering and technological supports (i.e. computational tools such as FiRECam - a fire risk assessment tool or FDS+Evac - a fire and evacuation modelling tool). Therefore, this paper intends to highlight that understanding of fire safety engineering is important for adoption of performance-based approach. For this purpose, an agent-based fire evacuation modelling tool (FDS+Evac) is presented in order to show its capability and possibility in helping the design decision for fire safety in a building.

\subsection{EVACUATION MODELS}

The emphasis on performance-based approach for fire safety design has increased the demand on evacuation models since 20th century. Evacuation models included both engineering hand calculation and computational tools (Kuligowski, 2008). Hand calculation is mainly focused on points of construction throughout the building and calculates the time for the occupants to move from one point to another and ultimately out of the building, treat the occupants as particles (Kuligowski et al., 2010). However, without considering other components such as interactions within individual, the building and fire condition, and the decision-making processes of the individuals, the calculations were unrealistic and inefficient. Therefore, engineers and researchers have been looking to simulate evacuation process using computer software to help them assess key aspects of a building's life safety attributes (Kuligowski et al., 2010). One of the important life safety parameters that can be quantified from those tools is the estimation of safe egress time, e.g. Available Safety Egress Time (ASET) and Required Safety Egress Time (RSET) (Babrauskas et al., 2010; Fleischmann, 2009). ASET is the time from fire ignition to the time at which tenability criteria are exceeded. Whereas, RSET is the time from fire ignition to the time at which occupant reach a safe place. In order to make sure the occupants' life safety, RSET should not exceed ASET. Furthermore, computational evacuation models have been developed to analyse the risk of occupants expose to fire and smoke condition such as Fractional Effective Dose (FED) that featured prominently in CRISP - a model developed by Fraser-Mitchell (1994).

There are 26 evacuation models reviewed by Kuligowski et al. (2010). Those models range from an efficient use of the hand calculations to models that have complex equations and occupants with decision-making capabilities. All these models, regardless of their availability, are developed with specific building occupancies, modelling techniques and validation strategies. Therefore, users must be aware when choosing a suitable model for their project, considering the types of building, fire effects, and the way of human behave based on the conditions and scenarios of their cases. There are also other features 
that are built in the models in order to account for different interactions of human behaviour, such as crowd or social behaviour, pre-evacuation time, route choice and others.

Currently, behaviour can be defined in evacuation models by three main techniques (Kuligowski \& Gwynne, 2010). Firstly, the behaviour is prescribed entirely by the user. This technique required user to input the information of the behaviour into the evacuation model based on assumption or definite data obtained from empirical fire cases or fire drills. The input informations that can be assigned by the user are the movement speed, route choice, delay time that represent pre-evacuation time, or even a sequence of actions of an individual or group. The evacuation model can assess the consequence of specified behaviour instead of predicting the probability of the occurrence of the behaviour. However, no behaviour will be simulated if the information is not input by the user. In addition, expertise judgment is required in the input information if there is no definite empirical data provided.

Secondly, behaviour is simulated in the evacuation model based on a specific condition. An 'if-then' statement is needed to provide by the user into the model (e.g. if an individual or a group of evacuees encounter condition A, then the individual or group will do action B). In this technique, behaviour will not necessary occur (deterministically) when the condition is encountered. It may occur based on a specified probability distribution (probabilistic). Therefore, this technique not only requires the input information provide by user, it also requires the role from the evacuation model to randomly choose a value from the provided probability distribution. For example, when evacuees encounter the cues from building (e.g. fire alarm), environment (e.g. smoke density) or other simulated individual/group (e.g. movement of individual or group), they will either stay static or start to move to evacuate based on a certain probability distribution. However, similar to the first technique, this technique required a high level of expertise judgment from the user as the condition that prompt the behaviour to occur will required to prescribe by the user.

Finally, behaviour is simulated based on the influence of multiple factors. The simulation of the behaviour in this technique is almost similar to the second technique. The simulated behaviour of the individual/group is affected by a series of factors throughout the evacuation process. In this technique, user is required to input the threshold values for those factors, e.g. critical smoke concentration, preference levels of occupants to wait at the crowded doorway before re-select the route or exit, occupant's knowledge on exit and evacuation route, etc. For instance, the exit and route choice selection of the evacuee is influenced by factors, such as the smoke concentration at the exit door or corridor, the crowd level at the doorway, the occupant's familiarity of building layout, or the information about the exit (e.g. signage). This may lead to redirection of exit selection when evacuee encounter the smoke density has exceeded the threshold value provided by user.

\subsection{Human Behaviour}

Human behaviour is one of the complex factors in evacuation modelling due to the stochastic nature of human decision-making in real world. Data on human behaviour in evacuation have been obtained based on variety of sources over several decades (Bryan, 2002a) and was summarized into "Behavioural Facts" (Gwynne, 2012; Kuligowski \& Gwynne, 2010) as shown in Figure 1. However, Kuligowski and Gwynne (2010) claimed that these separated behaviour used in current evacuation analysis have little attempt of connection between behaviour and no understanding on reason they occur. This may result in significant gaps in simulated occupant response.

Due to the limitation, a comprehensive behavioural conceptual model as shown in Figure 2 was proposed (Kuligowski, 2008). This model shows the process of human behaviour from phase of receiving cue to occupant action. Based on the model, occupant action is resulting from perception, interpretation of cue and decision made by occupant. All the phases are influenced by related factors from the surrounding environment or occupant's own characteristics. 
Behavioural fact \#1: People's first instinct is to feel safe in their environment.

Behavioural fact \#2: Perception of information is critical as it influences the information available and the manner in which it is prioritised. The information used is not simply contingent on the information available.

Behavioural fact \#3: People will engage in information seeking actions, especially when cues are ambiguous and/or inconsistent.

Behavioural fact \#4: People will not necessarily reduce their exposure to hazardous conditions.

Behavioural fact \#5: People act rationally and altruistically during building fires.

Behavioural fact \#6: People do not instantaneously switch to a different set or behavioural rules and roles unless provoked by the most extreme environmental condition.

Behavioural fact \#7: People are likely to engage in preparation activities before beginning their evacuation response (e.g., stair travel, elevator travel, etc).

Behavioural fact \#8: Once they begin evacuation movement, people move to the familiar.

Behavioural fact \#9: The surrounding population will influence the individual's decision-making process.

Behavioural fact \#10: People are heterogeneous, i.e. people have different physical, social, sensory and cognitive abilities.

Figure 1:"Behavioural Facts"

Source: Gwynne (2012); Kuligowski \& Gwynne (2010)

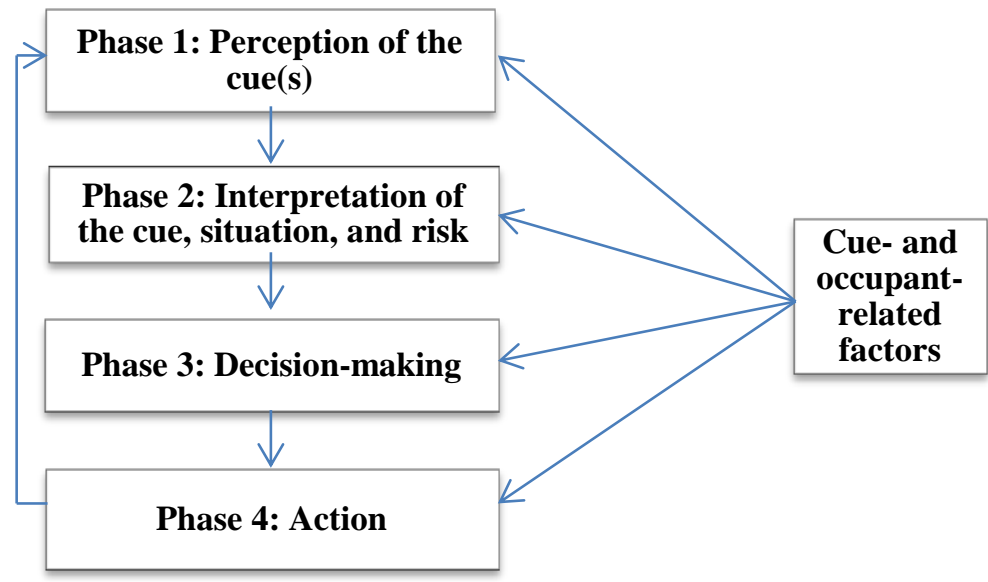

Figure 2: Conceptual Model

Source: Kuligowski (2008) 


\subsection{Factors Affecting Human Behaviour}

In general, there are three (3) main factors that would influence the human behaviour in building fire (Kobes et al., 2010a; Proulx, 2001). As shown in Figure 3, human characteristic is one of the factors that directly influence the behaviour of occupant. This includes the parameters of occupant profile, such as the age, gender, and mobility. The occupant's familiarity on building layout will also affect their exit and route choice selection for evacuation. Past fire experience or fire safety training (e.g. fire drill) will influence the decision-making and reaction of occupants during the building fire and evacuation process. The condition at the time of fire event, either awaking or sleeping, alone or with others, would affect the potential of the occupant to react. Different personality of occupants will lead to different behaviour, e.g. occupant with leadership would lead others during evacuation, while the follower would follow others. In a building, there are different role of people (e.g. owner, employee or visitor). When a fire alarm was triggered, the management of the building may take the responsible to investigate the alarm and even fight the fire if possible.

Human characteristic
- Profile
- Knowledge and
experience
- Condition at the time of
event
- Personality
- Role and responsibility
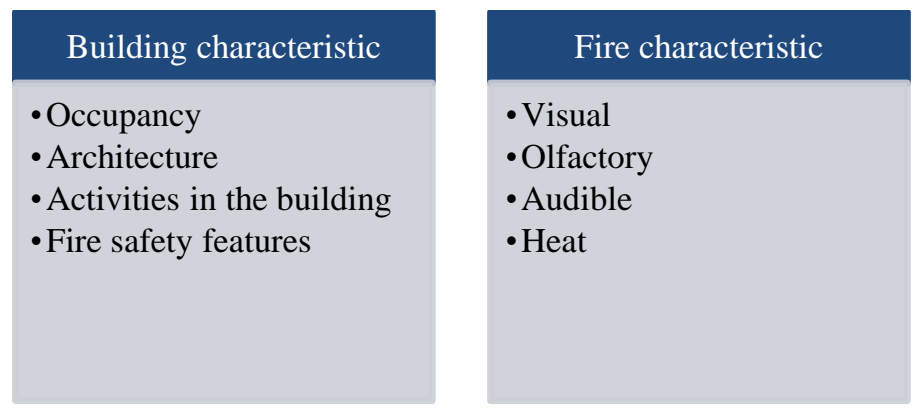

Figure 3: Factors of human behaviour in building fire Source: Proulx (2001)

Building characteristics include the type of building occupancy, the design of the building and the installation of fire protection systems. Different types of building will have different activities and this would also influence the condition of the occupant at the time of fire event. For example, in an office building, occupants are in a working condition. This may lead to quicker reaction if compared to a residential building, where occupants are in relaxing mode. It is even more critical if it was at night where occupants are sleeping. Building architecture is important for an efficient evacuation process. In a complex design, occupants may find difficulty in way finding. Therefore, it is important to have a clear design of mean of escape. Other than building design, the fire protection system is one of the major elements to alert occupants on fire, to slow down the fire growth rate or to provide a temporary shelter (e.g. refuge area) to occupants who do not have capability to evacuate out from the building. Fire safety management of the building is also important to provide the information of the current building condition to the occupant, the fire safety plan, or trained staffs in helping the evacuees during the evacuation.

In the event of fire in building, occupants may receive different cues from the fire and this would influence their perception and interpretation on the situation, hence influencing their behaviour. Fire cues can be perceived by direct visual of the flame or smoke, the smell of the smoke or toxic gases, hearing of cracking sound (e.g. cracking of window glasses due to flashover fire), and also feeling of heat.

\subsection{Human Behaviour in Evacuation Model}

Applying human behaviour into evacuation models, researchers are aiming to produce the results as realistic as possible. According to literatures, human behaviours in fire evacuation that can be modelled by current evacuation models are pre-evacuation time, route choice and exit selection, behaviour due to fire and smoke condition, crowd/social behaviour, to name but four. These behaviours can be stipulated in a form of input database or modelling output. Researchers have conducted various researches in order to investigate the human behaviour, to establish method to simulate those behaviours in evacuation models, to validate the established behaviour in those models, and to evaluate human behaviour using the evacuation models as listed in Table 1. These researches are aimed to establish those evacuation models that allowed the analysis on the performance of fire safety design and to mitigate the risk of building fire, specifically to achieve goal of life safety of occupants. 
Table 1: Human Behaviour in Current Evacuation Models

\begin{tabular}{|c|c|c|}
\hline Literatures & Behaviours & Explanations \\
\hline $\begin{array}{l}\text { Brennan (2000) } \\
\text { Spearpoint (2004) } \\
\text { Ko \& Spearpoint (2003) } \\
\text { Ko et al. (2007) } \\
\text { Heliövaara (2007) } \\
\text { Kobes et al. (2010b) } \\
\text { Augustijn-Beckers et al. } \\
\text { (2010) } \\
\text { Mu et al. (2013) }\end{array}$ & $\begin{array}{l}\text { Pre-evacuation } \\
\text { time } \\
\text { - Detection time }\end{array}$ & $\begin{array}{l}\text { - Fire cue or detection of fire. Occupants detect } \\
\text { fire by direct fire, smoke, alarm, inform by } \\
\text { other or observe on the other occupant's } \\
\text { response. } \\
\text { - Delay before occupants start to evacuate. } \\
\text { This may due to firefighting, informing } \\
\text { others, collecting belonging or not aware of } \\
\text { fire. } \\
\text { - Evacuation models are usually allowed the } \\
\text { delay time to represent the time of pre- } \\
\text { evacuation behaviour. }\end{array}$ \\
\hline $\begin{array}{l}\text { Ko \& Spearpoint (2003) } \\
\text { Huang et al. (2006) } \\
\text { Heliövaara (2007) } \\
\text { Smith \& Brokaw (2008) } \\
\text { Ehtamo et al. (2010) } \\
\text { Augustijn-Beckers et al. } \\
\text { (2010) } \\
\text { Roan et al. (2011) } \\
\text { Lim (2011) }\end{array}$ & $\begin{array}{l}\text { Route choice and } \\
\text { exit selection }\end{array}$ & $\begin{array}{l}\text { This is affected by following factors: } \\
\square \text { Occupants' familiarity on building layout. } \\
\text { Occupants in residential or office building may } \\
\text { have better knowledge of building layout } \\
\text { compared to public building, such as complex } \\
\text { mall, hospital, etc. } \\
\square \text { Visibility of exit. } \\
\text { Occupant did not aware of the emergency exit. } \\
\square \text { Accessibility or blockage of route and } \\
\text { exit. } \\
\text { The blockage of route or exit influences the } \\
\text { occupant decision to change route. }\end{array}$ \\
\hline $\begin{array}{l}\text { Heliövaara (2007) } \\
\text { Fang et al. (2010) } \\
\text { Ronchi et al. (2011) } \\
\text { Tissera et al. (2012) }\end{array}$ & $\begin{array}{l}\text { Behaviour due to } \\
\text { fire or smoke } \\
\text { condition }\end{array}$ & $\begin{array}{l}\text { - Fire and smoke tend to affect human } \\
\text { behaviour. For example, smoke will reduce } \\
\text { the visibility of occupants and causes the } \\
\text { occupants to reduce their walking speed. } \\
\text { - This behaviour is usually represented in } \\
\text { evacuation models by providing the reduction } \\
\text { factor to the walking speed or providing a } \\
\text { definite value when evacuees encounter a } \\
\text { certain condition (e.g. the smoke density } \\
\text { exceed the threshold value) }\end{array}$ \\
\hline $\begin{array}{l}\text { Pan (2006) } \\
\text { Fridman \& Kaminka } \\
\text { (2006) } \\
\text { Heliövaara (2007) } \\
\text { Zaharia et al. (2009) } \\
\text { Chu, et al. (2012) } \\
\text { Pan et al. (2007) } \\
\text { Fridman et al. (2011) }\end{array}$ & $\begin{array}{l}\text { Crowd behaviour } \\
\text { or Social social } \\
\text { behaviour } \\
\text { - Interactions } \\
\text { between } \\
\text { individuals } \\
\text { - Grouping } \\
\text { behaviour }\end{array}$ & $\begin{array}{l}\text { Evacuees tend to interact with each other and } \\
\text { cause crowd behaviours. Crowd behaviours are } \\
\text { such as: } \\
>\text { Herding behaviour. } \\
>\text { Queuing behaviour that form } \\
\text { bottleneck at doorway. } \\
>\text { Competing behaviour. } \\
>\text { Counter flow. } \\
>\text { Gathering all members before } \\
\text { evacuate. }\end{array}$ \\
\hline Ronchi \& Nilsson (2013) & Others & $\begin{array}{l}\checkmark \text { Other behaviours such as the use of elevator } \\
\text { or staircase. } \\
\checkmark \text { Disability either temporary or permanent. }\end{array}$ \\
\hline
\end{tabular}

\subsection{AGENT-BASED FIRE EVACUATION MODEL}

In this paper, FDS+Evac fire evacuation tool is implemented to simulate the scenario of occupant evacuation. FDS+Evac is an open source agent-based evacuation software developed by researchers of VTT- a Technical Research Centre of Finland. It is an extended module of Fire Dynamic Simulator (FDS) - a Computational Fluid Dynamic (CFD) model for 
simulation of fire and smoke dynamics. By coupling evacuation model with FDS, FDS+Evac allowed users to simulate occupant evacuation in fire scenario (Korhonen et al., 2010).

This section explains on the implementation of evacuation model in the process of performance-based fire safety design. This includes providing a set of inputs to the model and the resulting output for further analysis.

\subsection{Tests Settings}

Before the FDS+Evac could able to predict various variables for the purpose of design decision for fire safety, users are required to provide sets of input to the tool. This is one of the essential stages as reliable empirical data and technical guidelines are required in order to obtain a more realistic outcome. Input setting included the data for fire, building and occupants. Data for fire (e.g. maximum heat release rate and fire growth rate) are required to generate the development of fire (i.e. known as design fire). Data for building includes the geometry of the enclosure, openings, and building facilities (e.g. ventilation system and fire protection system) that might effect on the behaviour of fire and occupants. Finally, data for occupants are provided to indicate the behaviour of occupants throughout the evacuation process (i.e. from pre-evacuation behaviour to behaviour during evacuation movement).

In this simulation, the input setting for the study is mainly based on the default setting of FDS+Evac and prescriptive codes or guidelines (BS EN 54-5:2000+A1:2003, BS PD 7974-4:2003, BS PD 7974-6:2004).

\subsubsection{Design fire}

The fire is deterministically designed using t-squared method with a fast fire growth rate. Based on the report from Hietaniemi and Mikkola (2010), the heat released rate (HRR) - the rate at which heat is generated by fire can be very large, up to tens of megawatts (MW). Therefore, upon the purpose of conservative estimation, HRR is set to be maximum 10MW. The fire is located as shown in Figure 4.

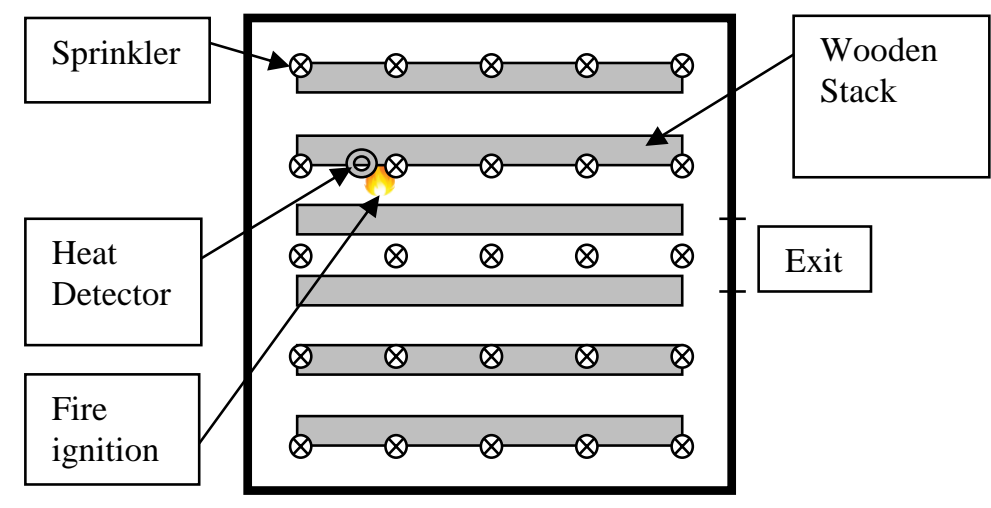

Figure 4: Scenario of Simulation

\subsubsection{Building design}

The simulated building is designed as a simple warehouse with size of $20 \mathrm{~m}(\mathrm{~L}) \times 20 \mathrm{~m}(\mathrm{~W}) \times 5 \mathrm{~m}(\mathrm{H})$. The building contain of six (6) rows of wooden stacks (16m x $1 \mathrm{~m} \mathrm{x} 2 \mathrm{~m}$ ) and one (1) exit door at the right side of building (Figure 4). There are one heat detector and 25 sprinklers installed in the building.

\subsubsection{Occupants (Workers)}

There are 50 workers that are randomly distributed within the boundary of simulated building. The body size and walking speed of workers are also randomly distributed according to the default (Adult) as shown in Table 2. Fire detection time of workers is defined at the time when the detector is activated. Besides, in this simulation, fire cue was also detected by the workers when the smoke density reached $0.1 \mathrm{mg} / \mathrm{m}^{3}$ at $2 \mathrm{~m}$ height. Pre-movement times of workers are defined in uniform distribution (low distribution $=30 \mathrm{~s}$, high distribution $=60 \mathrm{~s}$ ). Since the occupants are the workers in the warehouse, they are assumed to have knowledge about the building layout, especially location of exit door. 
Table 2: Default setting of walking speed and body dimension in FDS+Evac

\begin{tabular}{|l|c|c|}
\hline Body type & $\mathrm{R}_{\mathrm{d}}(\mathrm{m})$ & Speed $(\mathrm{m} / \mathrm{s})$ \\
\hline Adult & $0.255 \pm 0.035$ & $1.25 \pm 0.30$ \\
\hline Male & $0.270 \pm 0.020$ & $1.35 \pm 0.20$ \\
\hline Female & $0.240 \pm 0.020$ & $1.15 \pm 0.20$ \\
\hline Child & $0.210 \pm 0.015$ & $0.90 \pm 0.30$ \\
\hline Elderly & $0.250 \pm 0.020$ & $0.80 \pm 0.30$ \\
\hline
\end{tabular}

\subsection{RESULTS}

The result or output data obtained from the evacuation models are used to analyse the performance level of the fire safety design according to the client/stakeholder's goals. In this case, assuming one of the goals to achieve is life safety of occupants, the output data are used to compare with the performance criteria based on the estimation of tenability condition of occupants, known as tenability criteria.

From the simulation, various results were automatically generated by the tool. They are displayed in the form of video (Smokeview) and tabulated database (Spreadsheet). Figure 5 shows the snapshot of the simulation displayed in the Smokeview illustrating the response of fire/smoke and occupants at different time steps.

Picture (a) illustrates the fire ignition at $0 \mathrm{~s}$ as prescribed in the input data. Picture (b) illustrates the smoke released from the fire source at approximate $36.5 \mathrm{~s}$. During this period, occupants did not yet to realise the fire, hence no response was observed. At the time at approximate $1 \mathrm{~min}$ and $32.5 \mathrm{~s}$, the first occupant started to respond (red circled occupant start to move) as shown in picture (c). This may due to the fire cue where the smoke density reached $0.1 \mathrm{mg} / \mathrm{m}^{3}$ as stipulated in the input data. Other occupants were also respond and moving toward the exit (red arrows in picture (d)). The first occupant leaves the building at around $1 \mathrm{~min} 53 \mathrm{~s}$ (red circle in picture (d)), while the last occupants leaves the building at around $2 \mathrm{~min} 57.5 \mathrm{~s}$ (red circle in picture (e)). The smoke continues spreading and covered the whole building at time $4 \mathrm{~min} 44 \mathrm{~s}$ (picture (f)).
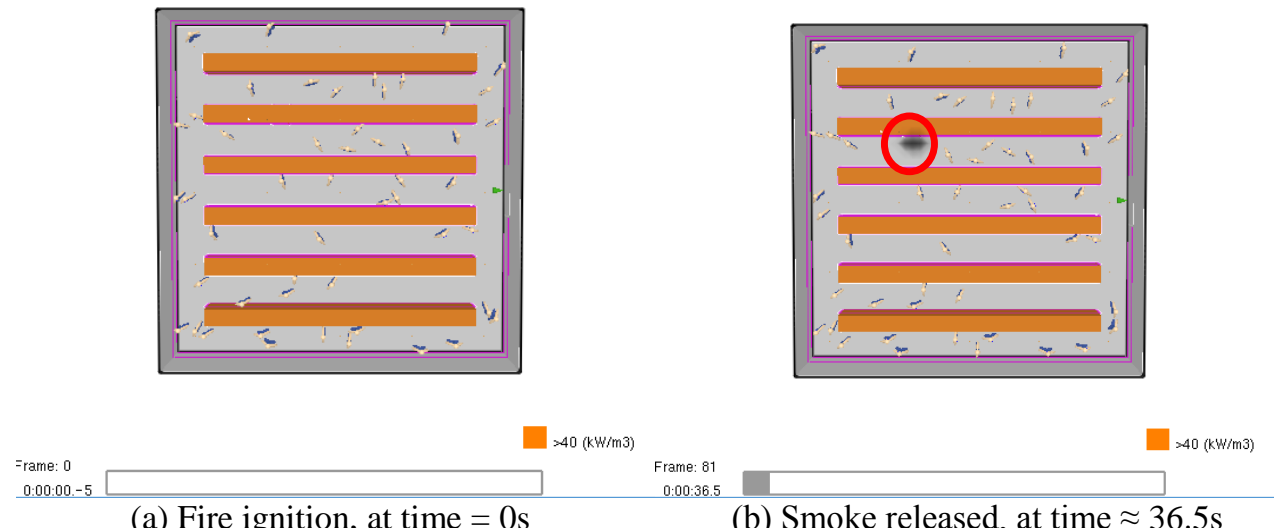

(a) Fire ignition, at time $=0 \mathrm{~s}$

(b) Smoke released, at time $\approx 36.5 \mathrm{~s}$

Smokeview 6.1.4 - Nov 42013

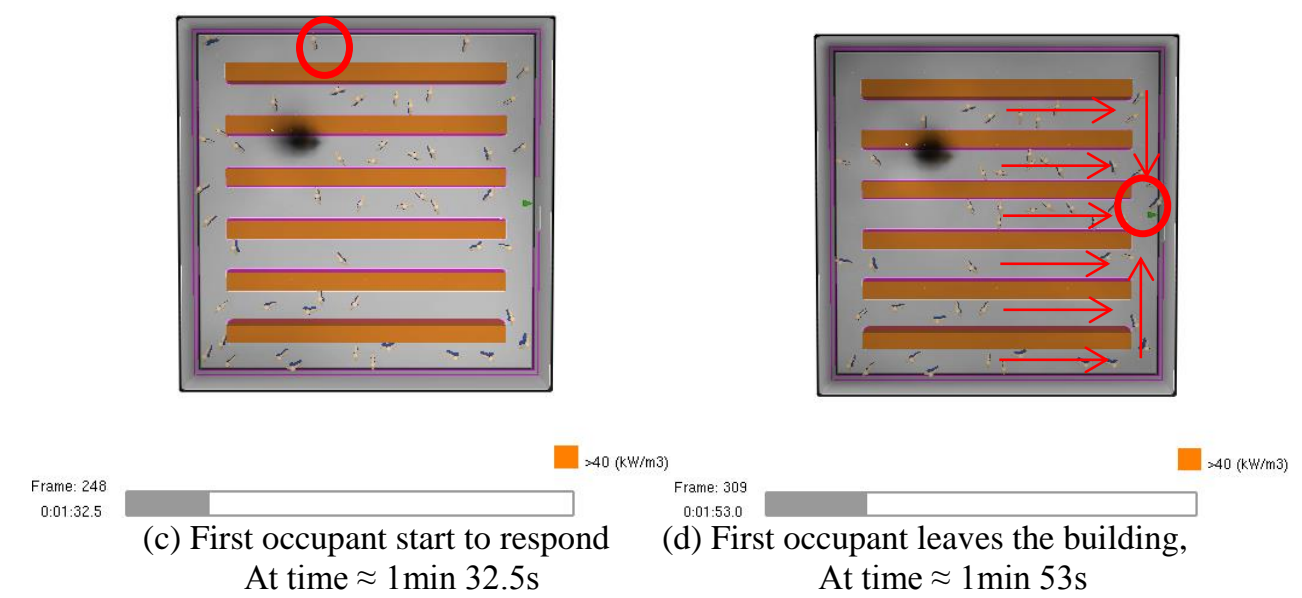

Smokeview 6.1.4 - Noy 42013 
Smokeview 6.1.4 - Nov 42013
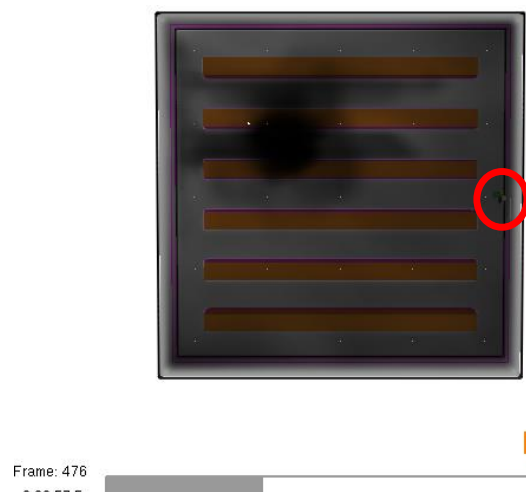

(e) Last occupant leaves the building, At time $\approx 2 \min 57.5 \mathrm{~s}$

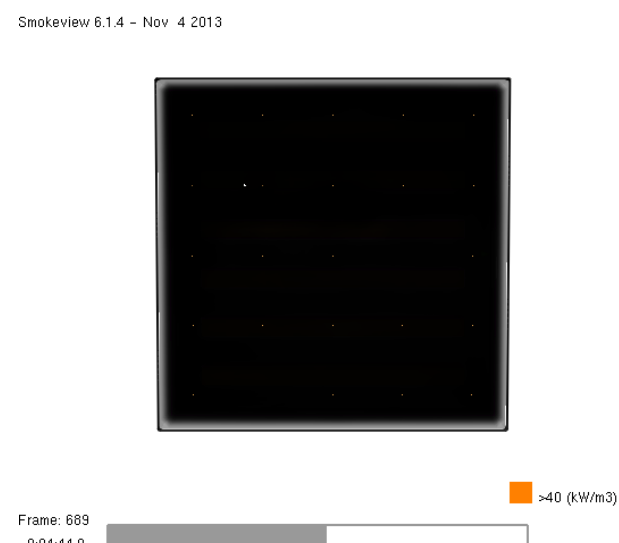

(f) Smoke spread and covered all over the building, at time $\approx 4 \min 44 \mathrm{~s}$

Figure 5: Smokeview of simulation

\subsection{Heat Released Rate}

Based on the initial setting (fast fire growth rate and max. 10MW HRR), FDS+Evac automatically generate the developments of fire from ignition, growing, fully-developed, and decay / burn out. These are illustrated in design fire curve as shown in Figure 6.

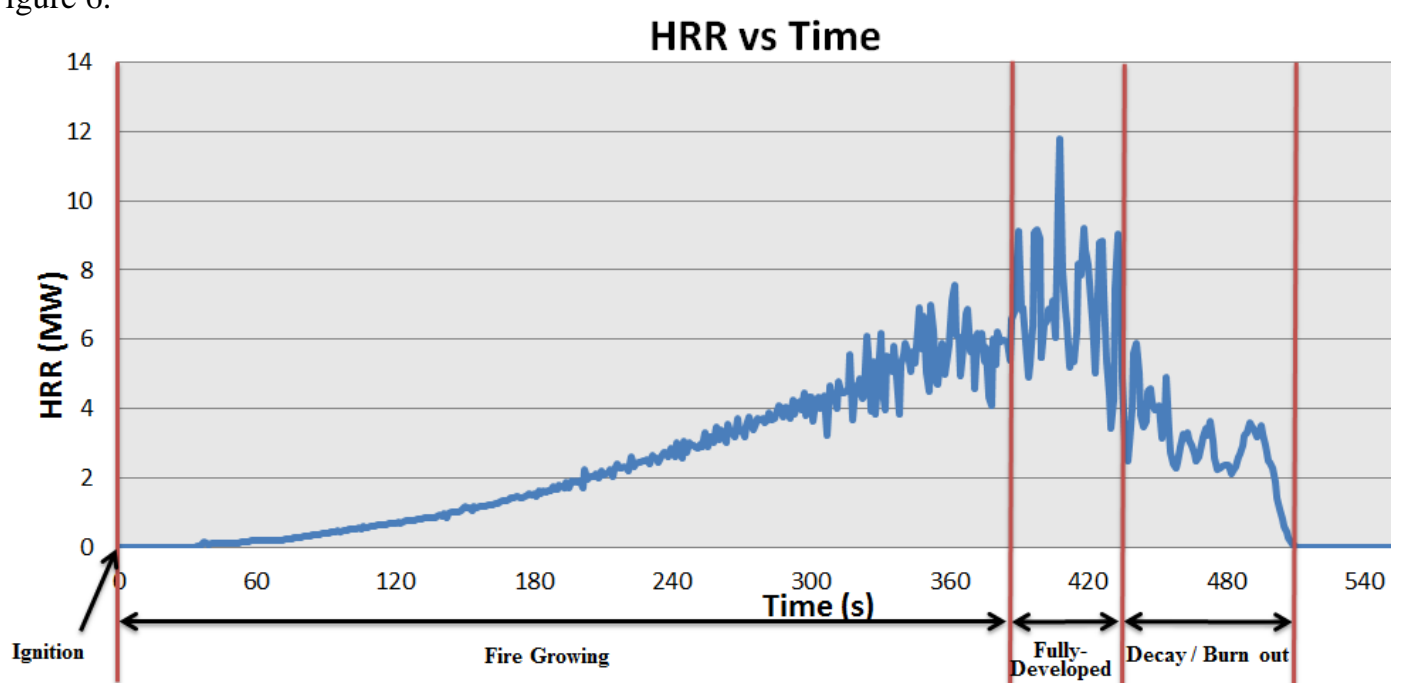

Figure 6: Design Fire Curve

Figure 6 shows the development of fire in terms of time-dependent HRR. The fire ignited at 0s, grow and fully develop at 390s. During the stage of fully-developed, the fire is average $7 \mathrm{MW}$ and started to decay at 430s after the fuels were burned out. During the input stage, the HRR value is set to be maximum 10MW. However, the effect of fire sprinklers has played a big role in reducing the heat, especially the average HRR value during the fully-developed stage.

\subsection{Evacuation time and FED}

The time-based comparison of ASET and RSET is a method to evaluate the life safety of occupants. To estimate the RSET in this simulation, evacuation time of the occupants are estimated from 0s (i.e. time of fire ignition) to the time of every occupants evacuated out of the building (i.e. reach a safe place). Figure 7 indicates the number of occupants remained in the building at every period of time. Evacuation time of each occupant can be estimated when the number of occupants in the building is decreasing. Similar to the video observation, the first occupant took around 110s to leaves the building and last occupant at around 180s. The total evacuation time is $180 \mathrm{~s}$. Evacuation time is affected by the behaviour of occupants, such as 
pre-evacuation time and movement time (e.g. walking speed, route choice and door choice, etc) that were defined during the input stage.

Then, the evacuation time is compared with the time the building has reached untenable condition (i.e. ASET). The ASET can be estimated based on tenability criteria. Tenability criteria provide the threshold values of the heat, smoke irritation and visibility, and toxic gases that will cause occupants incapacitation. Smoke irritation and visibility will only cause occupants to feel irritated and difficulty in moving. However, heat and toxic gases can cause occupants to death. Therefore, FED was adopted in FDS+Evac. FED is a calculation concept of toxic hazard, which assesses the effect of each toxic gas (i.e. Carbon dioxide, Carbon monoxide, etc.) on human in fire at any time. It was defined as the dose received at time $\mathrm{t}(\mathrm{Ct})$ over the effective $\mathrm{Ct}$ dose to cause incapacitation or death (Purser, 2002). Based on the tenability criteria stipulated in the performance-based building regulations (e.g. NRCC and NFPA), the threshold value of FED must be less than 0.3 in order for occupants to evacuate safely.

Concept of FED also can be used for heat, however the version of FDS+Evac used in this paper does not support the equation. Therefore, the FED values in this paper only represent the effect of toxic gases.

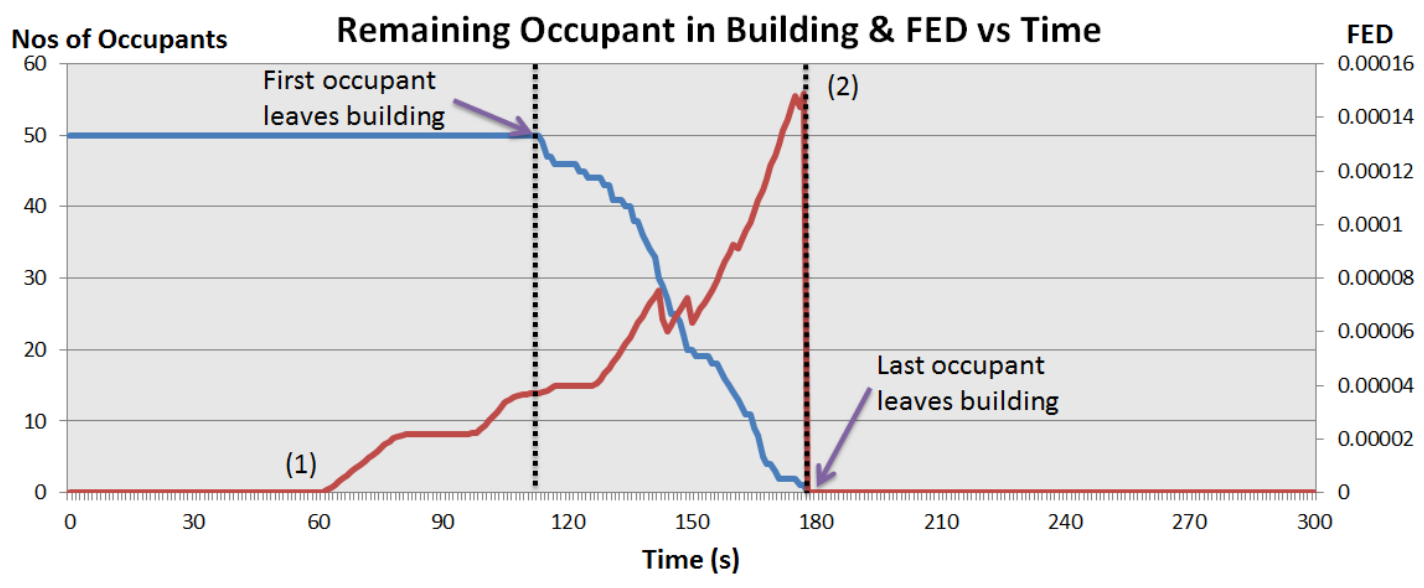

Figure 7: Evacuation time and FED

Figure 7 also illustrates the maximum FED value of occupants remained in the building. Note (1) indicates that occupants in the building exposed to the smoke at 60s. As time increased, FED increased due to increasing toxic gases exposed to the occupants. When the time the last occupant leaves the building, FED reached 0.00015 which is lower than the tenability criteria of FED $=0.3$. When FED reaches 1.0, occupants are assumed to be in incapacitation condition/death. Therefore, all occupants are able to evacuate out of the building safely in this simulation and there is neither injury nor death situation.

\subsection{CONCLUSION}

The adaptation of performance-based approach into Malaysian building code required various works to be done. One of these includes the understanding to analyses of the performance of fire safety design, such as use of fire dynamic tools, evacuation modelling tools to name but two. This paper presents the capability of evacuation modelling as a tool to assist designer, consultant or engineer in design decision for fire safety design. This paper introduced the evacuation models, human behaviour and its influencing factors, as well as the capability of current evacuation models in simulating human behaviour.

One of the technical issues in the process of performance-based fire safety design is related to the uncertainties of human behaviour. In real world, human behaviour in building fire is always unpredictable due to its stochastic nature. Therefore, it is very challenging when providing database into evacuation model in order to simulate a reliable outcome for fire safety design decision. That is why the understanding of human behaviour is important before one can simulate a fire evacuation scenario. Database of the human behaviour during evacuation in Malaysia is one of the areas that need to be developed because cultural differences play an important role in the perception of fire safety in different societies.

In this few decades, researches related to human behaviour in fire and evacuation model have brought a huge contribution to this field. More and more factors/capabilities were added into evacuation model (e.g. route choice/exit selection, influence of fire and smoke on human, pre-evacuation behaviour, crowd behaviour and choice of staircase/elevator for evacuation in high-rise buildings). Those researches have enhanced the capability of current evacuation model and tools were developed for designer to simulate fire evacuation scenarios during fire safety design performance analysis. 
Graphical representation of fire evacuation modelling output will help designers in understanding the fire phenomenon and the evacuation behaviour of human. In this simulation, the time-dependent HRR of the fire case was generated to imply the development of fire. As the fire ignited, HRR started to increase to its maximum value (i.e. fullydeveloped fire with average $7 \mathrm{MW}$ ) before decay after the burn out of fuel. The evacuation time of every occupant were obtained to estimate the RSET, which is 180 s in the simulation of this paper. The time-dependent FED is important in understanding the tenability condition of occupants for life safety purpose. The value of FED was compared with the tenability criteria and conclusion was estimated, where there is neither injury nor death. The simulation presented in this paper has shown how the life safety of the fire safety design could be predicted using an agent-based fire evacuation model. During performance-based fire safety design process, more design scenarios can be estimated with various designs. This has allowed designer to predict the performance of fire safety design and provide fire safety engineering solutions for the client/stakeholder in order to achieve their goals and objectives.

Fire safety design evaluation should be viewed as a whole, integrating all the factors involved. Not only the understanding of human behaviour in evacuation design and process is important, the essential knowledge of physical and chemical fire science and technology are very important as well. In other words, expert on fire safety and protection engineering is needed in Malaysia's context through education and training in order to adapt performance-based approach in the national regulation. Understanding of this knowledge is required by the users when using fire dynamic and evacuation tools so that the scenarios simulated or the results predicted are reliable. In fact, it is also important for all the people involved in the design team (e.g. designer, engineer, and AHJ) throughout the process of performance-based fire safety design.

\subsection{ACKNOWLEDGEMENT}

This work was supported by the University of Malaya Research Grant (Project No.: BK024-2011B; RG180-12SUS).

\subsection{REFERENCES}

Alvarez, A., Meacham, B., Dembsey, N., \& Thomas, J. (2013). Twenty years of performance-based fire protection design: Challenges faced and a look ahead. Journal of Fire Protection Engineering, 23(4), 249-276.

Augustijn-Beckers, E.-W., Flacke, J., \& Retsios, B. (2010). Investigating the effect of different pre-evacuation behavior and exit choice strategies using agent-based modeling. Procedia Engineering, 3, 23-35. doi: 10.1016/j.proeng.2010.07.005

Babrauskas, V., Fleming, J. M., \& Don Russell, B. (2010). RSET/ASET, a flawed concept for fire safety assessment. Fire and Materials, 34(7), 341-355.

Brennan, P. (2000). Modelling cue recognition and pre-evacuation response. Fire Safety Science, 6, 1029-1040. doi: 10.3801/iafss.fss.6-1029

Bryan, J. L. (2002a). Behavioral response to fire and smoke. SFPE handbook of fire protection engineering (3rd ed.). Quincy, MA: National Fire Protection Association (NFPA).

Bryan, J. L. (2002b). A historical review of human behavior in fire. Fire Protection Engineering, 7.

Chu, M. L., Law, K., \& Latombe, J. C. (2012). A computational framework for egress analysis with realistic human behaviors. USA: Stanford University.

Ehtamo, H., Heliövaara, S., Hostikka, S., \& Korhonen, T. (2010). Modeling evacuees' exit selection with best response dynamics. Pedestrian and Evacuation Dynamics 2008, 309-319.

Fang, Z.-M., Song, W.-G., Zhang, J., \& Wu, H. (2010). A multi-grid model for evacuation coupling with the effects of fire products. Fire Technology, 48(1), 91-104. doi: 10.1007/s10694-010-0173-x

Fleischmann, C. (2009). Prescribing the input for the ASET versus RSET analysis: Is this the way forward for performance based design? Paper presented at the Fire Protection and Life Safety in Building and Transportation Systems, Santander.

Fraser-Mitchell, J. (1994). An object-oriented simulation (Crisp 11) for fire risk assessment. Fire Safety Science, $4,793-804$. doi: 10.3801/iafss.fss.4-793

Fridman, N., \& Kaminka, G. (2006). Modeling crowd behavior based on social comparison theory. Cellular Automata, 694698.

Fridman, N., Zilka, A., \& Kaminka, G. A. (2011). The impact of cultural differences on crowd dynamics in pedestrian and evacuation domains. Israel: Bar Ilan University, Computer Science Department, MAVERICK Group.

Gwynne, S. M. (2012). Translating behavioral theory of human response into modeling practice. gaithersburg. MD: National Institute of Standard and Technology.

Heliövaara, S. (2007). Computational models for human behavior in fire evacuations. (M.Sc. Thesis), Helsinki University of Technology. Retrieved from http://virtual.vtt.fi/virtual/proj6/fdsevac/documents/heliovaara_msc_thesis.pdf

Hietaniemi, J., \& Mikkola, E. (2010). Design fires for fire safety engineering. VTT Working Papers. Retrieved from, http://www.vtt.fi/inf/pdf/ workingpapers/2010/W139.pdf 
Huang, H. C., Lo, S. M., Zhao, C. M., \& Wang, P. (2006 ). Simulation of occupant exit selection behavior during emergency evacuation using a game theory model. Paper presented at the 8th WSEAS Int. Conference on Automatic Control, Modeling and Simulation,, Prague, Czech Republic,.

Ko, S. Y., \& Spearpoint, M. (2003). Comparison of evacuation times using Simulex and EvacuationZ based on trial evacuations: Department of Civil Engineering, University of Canterbury.

Ko, S. Y., Spearpoint, M., \& Teo, A. (2007). Trial evacuation of an industrial premises and evacuation model comparison. Fire Safety Journal, 42(2), 91-105.

Kobes, M., Helsloot, I., de Vries, B., \& Post, J. G. (2010a). Building safety and human behaviour in fire: A literature review. Fire Safety Journal, 45(1), 1-11. doi: 10.1016/j.firesaf.2009.08.005

Kobes, M., Helsloot, I., de Vries, B., \& Post, J. G. (2010b). Exit choice, (pre-)movement time and (pre-)evacuation behaviour in hotel fire evacuation - Behavioural analysis and validation of the use of serious gaming in experimental research. Procedia Engineering, 3, 37-51. doi: 10.1016/j.proeng.2010.07.006

Korhonen, T., Hostikka, S., Heliövaara, S., \& Ehtamo, H. (2010). FDS+ Evac: an agent based fire evacuation model Pedestrian and Evacuation Dynamics 2008 (pp. 109-120): Springer.

Kuligowski, E. D. (2008). Modeling human behavior during building fires. Gaithersburg, MD: National Institute of Standards and Technology Technical.

Kuligowski, E. D., \& Gwynne, S. M. V. (2010). The need for behavioral theory in evacuation modeling. Pedestrian and Evacuation Dynamics 2008, 721-732. doi: 10.1007/978-3-642-04504-2_70

Kuligowski, E. D., Peacock, R. D., \& Hoskins, B. (2010). A review of building evacuation models (2nd Edition). US Department of Commerce, National Institute of Standards and Technology.

Lim, E. A. (2011). Exit-selection behaviors during a classroom evacuation. International Journal of the Physical Sciences, $6(13), 3218-3231$.

Meacham, B. (1996). The evolution of performance-based codes and fire safety design methods. Gaithersburg, MD: National Institute of Standards and Technology.

Meacham, B. (1999). International experience in the development and use of performance-based fire safety design methods: Evolution, current situation and thoughts for the future. Paper presented at the Fire Safety Science-Proceedings of the 6th International Symposium.

Mu, H. L., Wang, J. H., Mao, Z. L., Sun, J. H., Lo, S. M., \& Wang, Q. S. (2013). Pre-evacuation human reactions in fires: An attribution analysis considering psychological process. Procedia Engineering, 52, 290-296. doi: 10.1016/j.proeng.2013.02.142

Pan, X. (2006). Computational modeling of human and social behaviors for emergency egress analysis. (Doctoral dissertation), Stanford University.

Pan, X., Han, C. S., Dauber, K., \& Law, K. H. (2007). A multi-agent based framework for the simulation of human and social behaviors during emergency evacuations. Ai \& Society, 22(2), 113-132.

Proulx, G. (2001). Occupant behaviour and evacuation. Paper presented at the 9th International Fire Protection Symposium, Munich.

Purser, D. A. (2002). Toxicity assessment of combustion products. SFPE Handbook of Fire Protection Engineering, 3, 2-6.

Roan, T.-R., Haklay, M., \& Ellul, C. (2011). Modified navigation algorithms in agent-based modelling for fire evacuation simulation. Paper presented at the 11th International Conference on GeoComputation, London.

Ronchi, E., Gwynne, S., \& Purser, D. A. (2011). The impact of default settings on evacuation model results: A study of visibility conditions vs occupant walking speeds. Paper presented at the Evacuation and Human Behavior in Emergency Situations EVAC11, Santander.

Ronchi, E., \& Nilsson, D. (2013). Assessment of total evacuation systems for tall buildings. Lund: Lund University.

Scientific Fire Services. (n.d.). Projects/ overview. Retrieved from, http://www.scifire.com.au/projects.html

Smith, J. L., \& Brokaw, J. T. (2008). Agent-based simulation of human movements during emergency evacuations of facilities. Paper presented at the 2008 Structures Congress: Crossing Borders, Vancouver, British Columbia, Canada.

Spearpoint, M. (2004). The effect of pre-evacuation on evacuation times in the Simulex model. Journal of Fire Protection Engineering, 14(1), 33-53.

Tavares, R. M. (2009). An analysis of the fire safety codes in Brazil: Is the performance-based approach the best practice? Fire Safety Journal, 44(5), 749-755. doi: http://dx.doi.org/10.1016/j.firesaf.2009.03.005

Tissera, P. C., Printista, A. M., \& Luque, E. (2012). A hybrid simulation model to test behaviour designs in an emergency evacuation. Procedia Computer Science, 9, 266-275. doi: 10.1016/j.procs.2012.04.028

Zaharia, M. H., Leon, F., Pal, C., Pagu, G., Baykara, N., \& Mastorakis, N. (2009). Agent-based simulation of crowd evacuation behavior. Paper presented at the 11th WSEAS International Conference on Automatic Control, Modelling and Simulation, Stevens Point, Wisconsin, USA. 